\title{
A Erosão LinguísticA EM Italianos Cultos em Contato Prolongado com o Português do Brasil: Os Clí́ticos e Alguns EFEITOS NA ESTRUTURA DO ENUNCIADO \\ TOMMASO RASO Heloisa Pereira Vale
}

ABSTRACT: Questo lavoro esamina la perdita di alcuni pronomi clitici e il legame che tale perdita ha con particolari strutture sintattico-pragmatiche dell'enunciato in italiani colti in contatto prolungato con il portoghese brasiliano (PB). Dall'analisi di dati estratti da corpora di italiani monolingui, brasiliani monolingui e italiani bilingui emergono le considerazioni seguenti. Tutti i pronomi analizzati (lo accusativo, ci locativo e ne nei suoi vari valori) subiscono, sia pure in misura diversa, una perdita consistente. Al contrario abbiamo un aumento delle forme di esserci dovuto a strategie di semplificazione lessicale. L'analisi del pronome lo mostra, tuttavia, che non si ha riduzione, ma aumento di occorrenza, quando il pronome è anaforico di un costituente dislocato a sinistra. L’analisi della struttura dell'enunciato nei monolingui italiani e brasiliani mostra che in questi ultimi si ha una frequenza di gran lunga maggiore di tematizzazioni, il che spiegherebbe l'alta occorrenza del pronome nei bilingui quando esso è richiesto dalla principale strategia tematizzante in italiano.

PAROLE CHIAVE: erosione linguistica; sistema pronominale; struttura dell'enunciato; italiano; portoghese brasiliano. 
RESUMO: Este trabalho examina a perda de alguns pronomes clíticos e a ligação que essa perda mostra com algumas específicas estruturas sintático-pragmáticas do enunciado em italianos cultos em contato prolongado com o português do Brasil (PB). A partir da análise de dados extraídos de corpora de italianos monolíngues, brasileiros monolíngues e italianos bilíngues, emergem as considerações seguintes. Todos os pronomes analisados (lo acusativo, ci locativo e ne em suas várias funções) são perdidos em quantidade considerável, mesmo se em medidas diferentes. Ao contrário, notamos um aumento das formas de esserci devido a estratégias de simplificação lexical. A análise do pronome lo mostra, contudo, que não há redução, mas aumento das ocorrências, quando o pronome é anafórico de um constituinte deslocado à esquerda. A análise da estrutura do enunciado em monolíngues italianos e brasileiros mostra que estes últimos apresentam uma frequência muito maior de tematizações, o que explicaria a ocorrência alta do pronome nos bilíngues quando é requerido pela principal estratégia tematizante em italiano.

PALAVRAS-CHAVE: erosão linguística; sistema pronominal; estrutura do enunciado; italiano; português do Brasil.

ABSTRACT: This article studies attrition effects in some clitic pronouns and the link that such attrition presents with some particular syntantic-pragmatic constructions of the utterance in cultivate italians in long term contact with Brazilian Portuguese (PB). Analyzing data from corpora of monolingual Italians, monolingual Brasilians and bilingual Italians, it is possible to make the following observations: all the pronouns that were analyzed (accusative $l o$, locative $c i$ and the pronoun ne in all its functions) present attrition, even if in different degrees; the analysis of lo shows, however, that it does not undergo loss when the pronoun is an anaphoric left-cleft constituent, on the contrary, there are even more occurrences in such function; the analysis of utterance structure in monolingual Italians and monolingual Brazilians shows that for the latter there is a higher frequency of thematization, which could explain the higher occurrence of the pronoun in the bilinguals when it is mandatory in the main thematization strategy in Italian.

KEYWORDS: language attrition; pronominal system; utterance structure; Italian; 


\section{Objetivo do trabalho e contextualização}

.1 Este trabalho pretende examinar a erosão linguística do sistema pronominal clítico de italianos cultos em contato prolongado com o português brasileiro (PB). Em particular, a análise trata de dados relativos aos pronomes acusativos de terceira pessoa, aos $c i$ locativos, aos $c i$ atualizantes e lexicalizantes e aos ne, nos seus diversos valores, exceto os lexicalizantes. Os dados analisados foram extraídos de três tipologias de corpora diversas: um corpus de bilíngues compilado na Universidade de São Paulo (USP), ${ }^{1}$ dois corpora de monolíngues italianos, constituídos do LIP $^{2}$ e do corpus LABLITA, $^{3}$ e finalmente um corpus de monolíngues brasileiros constituído do NURC-Rio. ${ }^{4}$

A análise da erosão pronominal, conforme se verá, nos conduziu a identificar algumas funções pronominais que, desempenhando um papel importante nas estruturas de interface entre sintaxe e pragmática, revelam interessantes características da estruturação do enunciado no confronto a três entre brasileiros, italianos e bilíngues.

$1.2 \mathrm{O}$ conceito de erosão linguística é entendido, segundo a definição de Köpke e Schmid (2004, p. 5), como "non-pathological decrease in proficiency in a language that had previously been acquired by an individual, i. e. intragenerational loss". ${ }^{5}$ Entendemos por italianos cultos indivíduos que tenham vivido na Itália até a idade adulta, que tenham frequentado os estudos na Itália ao menos até o término da escola superior e que se tenham formado, na Itália ou em um outro país. Ter frequentado ao menos treze anos de escola na Itália garante uma plena aquisição da L1, evitando assim o risco de que os aparentes fenômenos de erosão sejam na realidade devidos a uma aquisição incompleta. $\mathrm{O}$ diploma de graduação permite pressupor uma competência metalinguística que garante

1.Publicado na Revista de Italianística, 1997. Esse corpus foi posteriormente ampliado durante o desenvolvimento de um projeto coordenado por Raso.

2. DE MAURO, 1993.

3. Disponível em: http://lablita.dit.unifi.it/corpora/.

4. Disponível em: http://www.letras.ufrj.br/nurc-rj/. Para as pesquisas sucessivas se poderá contar com o corpus C-ORAL-BRASIL (coordenado por T. Raso e H. Mello), que se apresenta como a quinta ramificação do C-ORAL-ROM (CRESTI-MONEGLIA, 2005), do qual segue arquitetura e critérios de segmentação.

5. Para uma discussão sobre os vários aspectos envolvidos no conceito de erosão, vejam-se ao menos Selinger e Vago, 1991; Cook, 2003; Schmid et al., 2004 . 
um grau suficiente de reflexão e controle sobre a própria produção linguística. Por contato prolongado com o $\mathrm{PB}$, em princípio, consideramos um período mínimo de permanência de oito anos, já que os estudos sobre a erosão parecem concordes em considerar que o processo de perda substancialmente se completa nos primeiros dez anos de permanência no exterior. ${ }^{6}$ Todavia, os dados relativos a este estudo foram todos extraídos de informantes que, no momento das entrevistas, no meado dos anos noventa, residiam no Brasil há pelo menos vinte anos, e em vários casos há muito mais tempo.

\section{2. $O$ sistema pronominal: aspectos em comparação}

\subsection{Os clíticos objeto de análise}

O sistema dos clíticos em italiano é, como se sabe, muito complexo. Mesmo sendo um dos principais sistemas em reestruturação no italiano contemporâneo, ${ }^{7}$ é sem dúvida possível definir o seu uso sincrônico. Este uso não encontra correspondência no uso brasileiro para nenhum dos clíticos examinados neste trabalho. A começar pelo pronome acusativo lo e suas várias formas, o equivalente do uso italiano exemplificado em (1):

(1) Ho comprato una camicia nuova, ma ancora non l'ho usata

pode ser tomado em PB com as variantes exemplificadas em (2)-(4), respectivamente com objeto nulo, pronome tônico e pronome clítico:

(2) Comprei uma camisa nova, mas ainda não usei

(3) Comprei uma camisa nova, mas ainda não usei ela

(4) Comprei uma camisa nova, mas ainda não a usei

O significado da expressão não muda minimamente em PB; a única diferença é que (4) é reservada ao registro escrito de média e alta formalidade e ao falado de formalidade muito alta. Disso deriva que (2) e (3) são muito mais usadas e juntas cobrem quase a inteira distribuição da diamesia oral e parte da diamesia escrita.

Para os outros pronomes a situação é muito similar, mesmo com algumas particularidades: conforme o pronome, o uso do clítico é impossível, como em (5) para exprimir a função locativa equivalente ao italiano ci, onde, porém, é possível uma recuperação adverbial do locativo, ou em (6) para exprimir o equivalente do ne partitivo:

6. Köpke e Schmid, 2004.

7. Sobre as tendências do sistema pronominal em italiano, cf. Vanelli, 1999; Berretta, 1994; Lorenzetti, 2002; Leone, 2003. 
(5) Sei già stato in Italia? Sì, ci sono stato l'anno scorso VS. Sim, fui (pra lá) o ano passado

(6) Di mele $\boldsymbol{n} \boldsymbol{e}$ ho comprati due chili VS. De maçãs comprei dois quilos

\subsection{Outros clíticos}

No caso do pronome reflexivo, do recíproco ou do pseudo-reflexivo, está em curso uma forte tendência à perda do pronome, que opera com força maior em certas diatopias (por exemplo na região de Minas Gerais), em diafasias mais coloquiais e em diastratias mais baixas, mas que está em expansão por toda parte e, com intensidades diversas, em todas as diafasias e diastratias. Os resultados possíveis variam, no entanto, segundo a função do pronome, mas também segundo o tipo lexical. No caso do reflexivo, podemos ter tanto a forma com o pronome quanto a sem o pronome, como em (7), mas alguns verbos podem selecionar apenas uma forma, como em (8) ou (9), ou ter forte preferência por uma das duas. Todavia, está claramente em expansão a forma sem o pronome, como mostram casos do tipo (10), em que tende a se expandir a forma sem o pronome, há poucas décadas ainda sentida sem dúvida como não gramatical.

(7) Mi sono asciugato bene VS. Enxuguei bem / Me enxuguei bem

(8) Mi lavo le mani VS. Eu lavo as mãos

(9) Si è ucciso = Ele $\boldsymbol{s e}$ matou

(10) $\boldsymbol{S i}$ è tagliato (con un coltello) VS. Ele se cortou (com uma faca) / Ele cortou (com uma faca)

Também para o recíproco está em forte expansão a forma sem pronome, que geralmente se põe ao lado, e não se substitui inteiramente, da forma com o pronome, como em (11) e (12). Naturalmente nem todos os verbos permitem a supressão do pronome, sob pena de mudança de significado; um caso extremo é o de (13):

(11) Si sono incontrati ieri VS. Eles encontraram ontem / Eles se encontraram ontem

(12) Si sono baciati VS. Eles beijaram / Eles se beijaram

(13) $\boldsymbol{S i}$ sono visti $=$ Eles $\boldsymbol{s e}$ viram

Muito interessante é o que se verifica para os pseudorreflexivos. Em (14), por exem- 
plo, é gramatical a forma sem o pronome, como em vários outros verbos. Note-se que em casos como esse a forma transitiva e a intransitiva do verbo são iguais; a desambiguação é devida ao contexto linguístico. Em (15), mesmo sendo preferida a forma pronominal, não é raro escutar aquela sem pronome também em falantes cultos:

(14) Si è tagliato i capelli VS. Ele cortou o cabelo

(15) Si è interessato molto al progetto VS. Ele se interessou muito pelo projeto / Ele interessou muito pelo projeto

Em síntese, o uso do PB registra uma forte tendência à eliminação dos clíticos, mais ou menos marcada conforme o pronome e a função, e em fase mais ou menos avançada segundo a variante regional, situacional e sociocultural. ${ }^{8}$ Destacamos que os informantes por nós utilizados para a presente pesquisa são todos residentes em São Paulo, área que tende a conservar os clíticos, e todos aprenderam o PB antes da metade dos anos setenta, quando o uso do pronome era muito mais comum.

\section{Dados e análise: os clíticos}

\subsection{Quadro geral}

A simples contagem das formas presentes sobre o total de 18.080 palavras para cada uma das três tipologias de corpora em textos comparáveis (essencialmente entrevistas) forneceu o quadro indicado na tabela 1 :

\section{TABELA 1}

\begin{tabular}{|l|c|c|}
\hline \multicolumn{1}{|c|}{ CLÍ́TICOS } & BILÍNGUES & $\begin{array}{c}\text { ITALIANOS } \\
\text { MONOLÍNGUES }\end{array}$ \\
\hline lo acusativo & $166(-45,4 \%)$ & 304 \\
\hline $\boldsymbol{c i}$ atualizante e lexicalizante & 120 & 117 \\
\hline $\boldsymbol{c i}$ locativo & $24(-38,4 \%)$ & 39 \\
\hline ne partitivo, locativo, argumental & $14(-52,8 \%)$ & 29 \\
\hline \multicolumn{1}{|c|}{ TOTAL } & $324(-33,8 \%)$ & 489 \\
\hline
\end{tabular}

8. Para o sistema pronominal do PB, ver Neves, 2000; Cunha e Cintra, 2001; Carvalho, 2002; Perini, 2002; Silva, 2002. Duarte (1989) nos mostra que a variação de uso resulta de condicionamentos linguísticos (morfológico, sintático e semântico) e extralinguísticos (social escolaridade e faixa etária - e estilístico). Câmara Júnior (1972) faz um interessante estudo comparativo sobre o sistema pronominal nas variantes portuguesa e brasileira do português, no qual assevera que o pronome tônico ele firmou-se como uma forma sintática invariável, que, à maneira dos nomes e dos demonstrativos, pode ser empregada em todos os casos, mesmo no acusativo, em que tomaria o lugar vazio deixado por $o$. Bagno (2001) aborda a distância entre a verdadeira língua falada e escrita pelos brasileiros cultos e a norma-padrão veiculada pelas gramáticas normativas. 
Observando os dados não desagregados, nota-se uma redução geral dos clíticos de cerca de $34 \%$, mais acentuada para o ne, no qual, porém, há menos ocorrências em números absolutos, e para o pronome acusativo de terceira pessoa (lo e as formas alternativas), pouco mais acentuado do que a média para o locativo ci, enquanto parece não haver erosão para o ci denominado atualizante e para o lexicalizante, que aqui vêm tratados juntos por comodidade expositiva. Desagregando os dados conclui-se, no entanto, que o quadro é bem mais complexo. Antes de verificar a situação em detalhe é necessário, porém, considerar que a redução do ci locativo poderia estar subestimada. Isto por causa do tema das entrevistas aos bilíngues, que trata em grande parte da passagem do lugar de origem à nova destinação brasileira e induz, portanto, uma maior frequência de sintagmas com função locativa e, consequentemente, uma sua retomada anafórica com o pronome. A particular natureza desses textos requer, portanto, uma verificação em outros textos. De qualquer forma, podese concluir que a perda de clíticos é, nesse caso, de pelo menos $38,4 \%$.

\subsection{A análise}

3.2.1 A desagregação dos dados é mais simples se partirmos dos pronomes ci com valor atualizante ou lexicalizante. A tabela 2 mostra, justamente, quão diverso é o quadro apresentado a partir das duas tipologias de falantes:

TABELA 2

\begin{tabular}{|l|c|c|}
\hline TYPES LEXICAIS & TOKENS BILÍNGUES & $\begin{array}{c}\text { TOKENS ITALIANOS } \\
\text { MONOLÍNGUES }\end{array}$ \\
\hline ESSERCI & $107(89 \%)$ & $57(42,7 \%)$ \\
\hline AVERCI & $10(8,3 \%)$ & $59(43,5 \%)$ \\
\hline ENTRARCI & 0 & 3 \\
\hline METTERCI & 1 & 1 \\
\hline GUADAGNARCI & 0 & 1 \\
\hline VOLERCI & 0 & 1 \\
\hline IMPIEGARCI & 0 & 3 \\
\hline RIMANERCI & 0 & 1 \\
\hline TENERCI & 1 & 0 \\
\hline SAPERCI FARE & 1 & 0 \\
\hline TOTAL TYPES & $\mathbf{3}$ & $\mathbf{6}$ \\
\hline TOTAL TOKENS & $\mathbf{3}$ & $\mathbf{1 0}$ \\
\hline
\end{tabular}


É fácil notar, observando a tabela 2, que a homogeneidade que os dados desagregados apresentavam é apenas aparente. Comparando o comportamento dos italianos monolíngues com o dos bilíngues, aparecem imediatamente três diferenças:

1. nos bilíngues a frequência de esserci é altíssima e constitui quase $90 \%$ das ocorrências. Naturalmente também nos italianos monolíngues a frequência de esserci é alta, mas se limita a $42,7 \%$;

2. ao contrário, a frequência de averci é de apenas 8,3\% nos bilíngues, enquanto nos monolíngues supera, mesmo que em pouco, a frequência de esserci e alcança 43,5\%;

3. por fim, enquanto nos bilíngues os types com ci lexicalizantes são apenas três, para um total de seis tokens, nos monolíngues são seis para um total de dez tokens. Nesse caso os números são pequenos e deverão ser verificados em um corpus maior, mas, como se verá, constituem uma indicação muito útil.

Uma distribuição tão diversa em números totais praticamente idênticos se explica, a nosso ver, do seguinte modo: a maior ocorrência de averci nos monolíngues em relação aos bilíngues é ligada ao diverso estatuto que a expressão reveste no italiano falado contemporâneo em relação ao da época de aquisição dos informantes bilíngues por nós considerados. Estes, como foi dito, na metade dos anos noventa já viviam no Brasil há pelo menos vinte anos, e em muitos casos há muito mais tempo. A forma averci foi substandard até poucas décadas atrás. É, portanto, compreensível encontrá-la bem representada em corpora como o LIP ou o LABLITA, mas não em um corpus de falantes que adquiriram o italiano antes da última grande guerra e emigraram para o Brasil entre os anos quarenta e o início dos anos setenta.

O enorme percentual de esserci nos bilíngues é provavelmente devido à erosão lexical. Na verdade esserci se presta como forma genérica para muitos verbos de estado, como mostra o fato de que o enunciado (16) pode perfeitamente prestar-se a substituir (17)-(19):

(16) Alla riunione c'erano anche due americani

(17) Alla riunione parteciparono anche due americani

(18) Alla riunione erano presenti anche due americani

(19) Alla riunione furono invitati anche due americani

Uma confirmação indireta de que o alto número de esserci deve ser fruto de estratégias de simplificação lexical se tem contando os casos nos quais esserci reveste uma precisa função informativa e possui valor apresentacional. ${ }^{9}$ Os casos de esserci apresentacional são precisamente 15 nos bilíngues e 11 nos monolíngues. Trata-se de uma diferença que, com estes valores absolutos, não é estatisticamente significativa.

\footnotetext{
9. Um exemplo de esserci com valor apresentacional é c’è un signore che vuole parlare con te (tem um senhor que quer falar com você), ao invés da forma un signore vuole parlare con te (um senhor quer falar com você). A forma apresentacional normalmente é explicada com base em princípios cognitivos-informacionais. O que se pensa é que ela torna mais leve cognitivamente uma estrutura muito pesada porque acumula muita informação nova. A forma um senhor quer falar com você impõe ao interlocutor o processamento de um referente novo e de uma informação nova sobre ele em tempos e elementos linguísticos mínimos. Ao contrário, a forma apresentacional oferece primeiro a informação sobre a existência de um referente novo e depois apoia sobre essa informação, que se torna de alguma maneira dada, a segunda informação.
} 
3.2.2 Observemos agora o que acontece se desagregarmos os dados relativos ao pronome acusativo lo. A tabela 3 ilustra um quadro mais detalhado.

TABELA 3

\begin{tabular}{|l|c|c|}
\hline \multicolumn{1}{|c|}{ CLÍ́TICOS } & BILÍNGUES & $\begin{array}{c}\text { ITALIANOS } \\
\text { MONOLÍNGUES }\end{array}$ \\
\hline Total pronomes acusativos $l o$, la, $l e, l i, l$ ' & $166(-45,4 \%)$ & 304 \\
\hline Em enunciados com deslocamento à esquerda & $29(+25 \%)$ & 23 \\
\hline Em enunciados com deslocamento à direita & $13(-54 \%)$ & 28 \\
\hline
\end{tabular}

A partir dos dados da tabela 3 podem-se imediatamente fazer as seguintes considerações: a perda média dos pronomes acusativos é de 45,4\%. Não há dúvida, portanto, de que os bilíngues tendem fortemente a perder o uso do clítico acusativo. Todavia, se observamos apenas os casos nos quais o clítico desenvolve uma função anafórica ou catafórica de um constituinte deslocado, ficamos surpresos. Com efeito, se contamos as ocorrências de pronomes em enunciados que apresentam constituintes deslocados à esquerda, onde o pronome tem função anafórica, nos damos conta de que as ocorrências nos bilíngues são superiores àquelas dos italianos monolíngues em $25 \%$. Vale dizer que, nesta função, não só não se verifica a perda que, em média, é de 45,4\%, mas se registra mesmo uma ocorrência superior. Isso de um lado nos diz que a perda de clíticos acusativos, se se excluem os casos de deslocamento à esquerda, deve ser maior do que $45,4 \%$, e de outro nos diz que o comportamento é diverso onde há deslocamento à esquerda e que tal comportamento deve ser explicado. Ao contrário, quando o pronome possui função catafórica de um constituinte deslocado à direita, a perda parece ser maior do que a média.

Deve-se dizer, além do mais, que a alta ocorrência de pronomes acusativos com função anafórica de constituintes deslocados não é incompatível com a erosão pronominal nesta função. No corpus inteiro de bilíngues, que é de cerca de 54.000 palavras, registramse de fato 12 casos nos quais é omitido o pronome com função anafórica em enunciados que apresentam deslocamento. Um caso é fornecido pelo exemplo (20), no qual a forma gramatical seria (21):

(20) Io mi sono resa conto che l'italiano lui poteva mantenere in casa

(21) Io mi sono resa conto che l'italiano lui lo poteva mantenere in casa 


\section{Dados e análise: as tematizações}

\subsection{Aspectos do sistema em contraste}

Para explicar a presença de um número tão elevado de clíticos em deslocamento à esquerda, não obstante os casos de perda do pronome anafórico documentados no corpus, fez-se necessária uma verificação sobre o modo de estruturar o enunciado nas duas línguas em contato e sobre as preferências de cada língua quando estão à disposição mais soluções para a mesma função. Em particular, já que o nosso exame tem como objetivo explicar o comportamento do pronome anafórico nos casos de deslocamento à esquerda, é importante observar quais são as estratégias de tematização de um constituinte colocado à esquerda no enunciado. $\mathrm{O}$ italiano conhece as estratégias exemplificadas em (22)-(24), respectivamente deslocamento, tema suspenso e anacoluto: ${ }^{10}$

(22) Francesco, lo vedo domani / A Francesco, gli ho fatto proprio un bel regalo

(23) Francesco, gli ho fatto proprio un bel regalo

(24) Le vacanze, non ho ancora preparato niente

Note-se que quando o constituinte deslocado é um objeto direto, o italiano não permite a omissão do pronome anafórico. O exemplo (22) seria agramatical se fosse como em (25), naturalmente atribuindo valor temático e não remático ao primeiro constituinte:

(25) *Francesco, vedo domani

Ao contrário, em PB é precisamente esta a estrutura mais usada, juntamente com aquela que prevê o uso do pronome tônico. A estrutura com o clítico anafórico é possível, mas pertence apenas a um registro alto e é usada quase exclusivamente no escrito de formalidade médio-alta. As três possibilidades são exemplificadas em (26):

(26) Francisco, eu vejo amanhã / Francisco, eu vejo ele amanhã / Francisco, eu o vejo amanhã

Os equivalentes em PB aos exemplos (23) e (24) do italiano são apresentados em (27) e (28). A forma mais usada para a retomada do constituinte dativo deslocado é com o pro- 
nome tônico e sem a marca de caso no primeiro constituinte. A outra forma é possível, mas menos usada no registro falado. Em nenhum caso é possível a retomada com o pronome que é, ao contrário, necessária em italiano:

(27) Francisco, eu dei um belo presente pra ele / Ao Francisco, dei um belo presente

(28) As férias, eu ainda não preparei nada

Acrescentamos outras duas informações sobre o $\mathrm{PB}$, não porque contribuam diretamente à discussão sobre os clíticos objeto em estruturas deslocadas, mas porque mostram o quanto é diverso o sistema do PB do sistema italiano relativamente ao uso dos clíticos e quão diversas são as forças que estão agindo e modificando os dois sistemas em direções muito diferentes. Em primeiro lugar, o PB, se de um lado está perdendo a série de clíticos objeto, ou quanto menos está reduzindo muito fortemente o seu uso, de outro está desenvolvendo uma série de clíticos sujeito, como acontece frequentemente nas línguas de expressão obrigatória do sujeito. De fato o $\mathrm{PB}$, contrariamente ao português europeu, já há algum tempo tomou o caminho de uma forte redução morfológica das pessoas verbais, que hoje, no falado coloquial, tendem cada vez mais a apresentar uma oposição entre a primeira pessoa singular e todas as outras. Está, de fato, cada vez mais em expansão um paradigma verbal do tipo eu faço VS. você/ele/nós (a gente)/vocês/eles faz. Consequentemente, caindo a marca de pessoa e número à direita, deve re-emergir à esquerda. Daqui o desenvolvimento de formas clíticas do pronome sujeito que têm motivação sintática. A segunda observação diz respeito à alta frequência do deslocamento à esquerda do sujeito temático com retomada pronominal. O exemplo (29) mostra um caso típico, no qual o pronome ele pode facilmente ser realizado como clítico:

(29) Carlos, ele nunca liga pra gente (Carlos, non ci dà mai retta)

\subsection{As topicalizações com valor temático nas três tipologias de falantes}

Considerados os dados fornecidos na tabela 3, a presença no corpus de algumas formas agramaticais que atestam a erosão pronominal também nas estruturas com deslocamento à esquerda, e vistas as diferenças entre $\mathrm{PB}$ e italiano na realização de enunciados com constituinte temático deslocado à esquerda, computamos as várias ocorrências dos diversos tipos de tematização tanto nos monolíngues italianos quanto nos monolíngues brasileiros e nos bilíngues, sobre um total de 11.000 palavras para cada uma das tipologias de corpora. O resultado está esquematizado na tabela 4: 
TABELA 4

\begin{tabular}{|l|c|c|c|}
\hline & $\begin{array}{c}\text { ITALIANOS } \\
\text { MONOLÍNGUES }\end{array}$ & BILÍNGUES & $\begin{array}{c}\text { BRASILEIROS } \\
\text { MONOLÍNGUES }\end{array}$ \\
\hline $\begin{array}{l}\text { Deslocamentos à } \\
\text { esquerda }\end{array}$ & 12 & 17 & 0 \\
\hline Temas suspensos & 1 & 2 & 4 \\
\hline Topicalizações temáticas & 2 & 7 & 38 \\
\hline TOTAL & $\mathbf{1 5}$ & $\mathbf{2 6}$ & $\mathbf{4 2}$ \\
\hline
\end{tabular}

A tabela 4 é bastante eloquente: o PB mostra uma frequência de tematizações quase tripla em relação ao italiano, em tipologias textuais absolutamente comparáveis. Os bilíngues situam-se em frequências intermediárias, como era de se prever. Mas é particularmente interessante analisar as diversas estratégias concretizadas pelas três tipologias de falantes para tematizar um constituinte à esquerda.

No PB nunca aparece o pronome anafórico do constituinte deslocado (portanto não se verifica a estrutura que denominamos "deslocamento à esquerda"), verificam-se mais casos de tema suspenso (todavia os números absolutos são pequenos demais para tirarmos conclusões seguras), mas o que surpreende é que a quase totalidade de tematizações é constituída de topicalizações temáticas, vale dizer de estruturas nas quais se perde cada relação sintática entre o elemento tematizado e o resto do enunciado, mantendo-se apenas uma relação de ordem funcional. Em (30)-(33) oferecemos alguns exemplos típicos desta estratégia em PB:

(30) As freiras, a gente morria de rir (Le suore, noi morivamo dal ridere)

(31) O resto do comércio, havia loja de móveis, havia farmácia (Il resto del commercio, c'erano negozi di mobili, c'era una farmacia)

(32) Corrida de cavalo, eu nunca fui ao Jockey Club (Corse di cavalli, non sono mai stato al Jockey Club)

(33) Porque um primário bem feito, tudo fica mais fácil, não? (Perché delle elementari fatte bene, tutto diventa più facile, no?)

Os monolíngues italianos têm preferências opostas: a quase totalidade das tematizações é constituída de deslocamentos, exatamente a estratégia nunca usada pelos 
monolíngues brasileiros; os poucos casos restantes parecem mostrar uma certa preferência pelo tema suspenso em relação à topicalização. Em geral pode-se dizer que o italiano prefere marcar sintaticamente a relação entre constituinte deslocado e resto do enunciado.

Quanto aos bilíngues, o seu comportamento se situa em uma posição intermediária que, entretanto, precisa ser compreendida nos detalhes: é verdade que se verifica um aumento dos casos de tematização em relação aos italianos monolíngues, acompanhado também por uma maior disponibilidade a enfraquecer as relações sintáticas; isso se constata um pouco pelo maior número de temas suspensos (mas se trata de um número de casos reduzido demais para induzir a conclusões confiáveis), mas sobretudo pelo número de topicalizações, que é mais do que o triplo em relação aos monolíngues italianos. Todavia não se pode não notar que a estratégia largamente preferida permanece o deslocamento, que, mesmo sem o aporte das outras estratégias, por si só já mostra um aumento das tematizações relativamente aos monolíngues italianos.

Estas observações nos permitem agora explicar uma presença tão marcante de pronomes clíticos objeto em posição anafórica de constituinte deslocado, não obstante a forte tendência dos bilíngues a perder os clíticos. Podemos agora dizer com razoável certeza que não se verifica um aumento dos clíticos nos deslocamentos, mas um aumento significativo dos deslocamentos devido a um aumento geral das estratégias tematizantes. Este aumento é tão evidente que, apesar de um número reduzido de casos de perda do clítico em deslocamento, o número absoluto dos clíticos em deslocamento resulta de qualquer modo mais elevado do que nos monolíngues italianos.

\subsection{Os deslocamentos à direita}

Resta ainda explicar por qual razão nos casos de deslocamento à direita a redução dos pronomes é superior à média e não se verifica o que acontece para os deslocamentos à esquerda. Em primeiro lugar é necessário dizer que, se do total dos pronomes clíticos excluíssemos os casos de pronomes anafóricos de constituintes deslocados à esquerda, o percentual de perda nos bilíngues se elevaria ulteriormente. Isso nos induz a reputar que nos deslocamentos à direita não se verifique uma perda maior, mas simplesmente se mantenha substancialmente o mesmo percentual de erosão dos outros contextos, excluído o dos deslocamentos à esquerda. De qualquer forma, tentamos explicar por que o comportamento do pronome tem efeitos tão diversos nos deslocamentos à esquerda e nos deslocamentos à direita.

Em italiano o deslocamento à direita pode ser realizado com ou sem quebra prosó- 
dica antes do constituinte deslocado, respectivamente como nos exemplos (34) e (35). Em $\mathrm{PB}$, diversamente, o deslocamento à direita pode ser realizado apenas com a quebra prosódica, como em (36), a partir do momento em que, não havendo catáfora pronominal, a quebra prosódica é a única marca que distingue a estrutura deslocada da estrutura canônica:
(34) L'ho mangiato / il pollo
(35) L’ho mangiato il pollo
(36) Eu comi / o frango

O exemplo com o verbo mangiare ajuda a discutir uma outra questão relativa ao deslocamento à direita. Verbos como mangiare podem ter mais estruturas argumentais. Em particular, mangiare possui uma possibilidade monoargumental como em (37) e uma a dois argumentos como em (38):

(37) Hai mangiato o non hai avuto tempo?

(38) Hai mangiato il frutto esotico che ti ho portato?

Na leitura a dois argumentos parece que o elemento deslocado deve ser necessariamente precedido do pronome e não pode ser marcado apenas por meio da quebra prosódica. Não parece aceitável encontrar quem nos tenha trazido a fruta exótica e proferir (39), ao passo que é perfeitamente aceitável (40):

(39) *A proposito, poi ho mangiato / il frutto esotico

(40) A proposito, poi l'ho mangiato / il frutto esotico

Todavia, na leitura monoargumental, é aceitável responder a (37) com (41):

(41) Ho mangiato / il pollo

Diversamente, em nenhum caso seria possível deslocar à esquerda um constituinte com valor temático sem a retomada pronominal. Mas o deslocamento à direita pode confundir-se também com o eco marcado prosodicamente. Por exemplo, um verbo como attraversare, que tem apenas estrutura a dois argumentos, pode ser aceitavelmente usado em um enunciado como (42) quando o contexto o permita, como no pequeno diálogo em (43):

(42) Ha attraversato / la strada

(43) A: Per favore, avvisami appena Mario ha attraversato la strada.

B: Ecco, ha attraversato / la strada 
Esta discussão nos serve para apresentar uma hipótese de explicação sobre o diverso destino do clítico no falar dos bilíngues conforme seja anafórico ou catafórico de constituintes deslocados. No PB o clítico não comparece em ambos os casos, portanto o papel da interferência é igual. Todavia, se os bilíngues parecem seguir de maneira significativa o modelo do $\mathrm{PB}$ quando o pronome é catafórico, isso não ocorre quase nunca se o pronome é anafórico e o constituinte deslocado se encontra à esquerda. Tal poderia se explicar com o fato que o deslocamento à esquerda sem pronome em italiano não é aceitável, enquanto para o deslocamento à direita a situação é mais complexa: em certos casos, como nos verbos com estrutura monoargumental, é aceitável; além disso, estruturalmente a semelhança entre o deslocamento e o eco é muito forte. Isso facilita a percepção de que o modelo do $\mathrm{PB}$ possa funcionar também em italiano e, com efeito, em determinados casos a percepção é correta. Isto posto, é perfeitamente compreensível que o pronome se perca mais quando a omissão ou não compromete a aceitabilidade do enunciado ou gera estruturas cuja aceitabilidade ou menos deve ser avaliada no contexto individual, e não, como no caso do deslocamento à esquerda, com base na estrutura em si.

\section{Algumas conclusões provisórias}

Neste trabalho apresentamos alguns dados relativos à perda dos pronomes clíticos em italianos cultos em contato prolongado com o PB. Resulta que os clíticos, com frequência diversa, perdem-se em todas as formas examinadas, exceto na função atualizante de esserci pela ação da erosão lexical e a forte disponibilidade desta forma a substituir escolhas lexicais mais precisas. Notamos, porém, que o pronome acusativo aparece com uma frequência extremamente alta quando é anafórico de constituintes deslocados à esquerda. Tal foi explicado com o forte aumento de estruturas tematizantes nos bilíngues, que tenderiam, nesse aspecto, em direção ao modelo produzido pelo PB. Ao contrário, quando o pronome é catafórico de constituintes deslocados à direita, não mostra uma resistência maior do que a média.

Uma pergunta que se põe é a seguinte: qual força, verdadeiramente, produz erosão? Se invocamos a interferência, podemos explicar a geral redução dos pronomes, a tendência a aumentar as estruturas tematizantes, mas não o fato que o pronome anafórico se conserve tão bem nestas. Poderíamos apontar uma geral tendência a preferir soluções mais pragmáticas e menos complexas gramaticalmente. Isso explicaria o aumento das estruturas tematizantes e a forte redução do complexo sistema de clíticos quando estão 
disponíveis soluções alternativas. Quando, ao invés, o sistema impõe com clareza o uso do clítico e não fornece soluções alternativas aceitáveis, este é mantido. Aqui nos limitamos a concluir que o estudo do sistema pronominal do italiano nos parece particularmente indicado a explorar os efeitos da erosão e as suas causas mais profundas. Mas para isso é necessário ampliar o número de pronomes estudados, o seu contexto de uso, as diversas funções e a quantidade de dados.

\section{Referências bibliográficas}

BAGNO, Marcos. Dramática da língua portuguesa: tradição gramatical, mídia \& exclusão social. 2. ed. São Paulo: Loyola, 2001.

BAGNO, Marcos. (Org.). Linguística da norma. São Paulo: Loyola, 2002.

BERRETTA, Monica. Il parlato italiano contemporaneo. In: SERIANNI, Luca; TRIFONE, Pietro (Orgs.). Storia della lingua italiana: scritto e parlato. Torino: Einaudi, 1994. v. 2, p. 239-270.

CÂMARA JÚNIOR, Joaquim Mattoso. Ele como um acusativo no português do Brasil. In: UCHÔA, Carlos Eduardo Falcão (Org.). Dispersos de J. Mattoso Câmara Jr. Rio de Janeiro: Fundação Getúlio Vargas, 1972. p. 47-53. (Série Dispersos n. 1).

CARVALHO, Orlene Lúcia de Saboia. Variação linguística e ensino: uma análise dos livros didáticos de português como segunda língua. In: BAGNO, Marcos. (Org.). Linguística da norma. São Paulo: Loyola, 2002..

COOK, Vivian (Org.). Effects of the second language on the first. Clevedon: Multilingual Matters, 2003.

CRESTI, Emanuela; MONEGLIA, Massimo (Orgs.). C-ORAL-ROM. Integrated Reference Corpora for Spoken Romance Languages. Amsterdam: John Benjamins, 2005.

CUNHA, Celso; CINTRA, Luís F. Lindley. Nova gramática do português contemporâneo. 3. ed. rev. 10. impressão. Rio de Janeiro: Nova Fronteira, 2001.

DE MAURO, Tullio (Org.). Lessico di Frequenza dell'Italiano Parlato. Milano: ETAS Libri, 1993.

DUARTE, Maria Eugênia Lamoglia. Clítico acusativo, pronome lexical e categoria vazia no português do Brasil. In: TARALLO, Fernando (Org.). Fotografias sociolinguísticas. Campinas: Pontes: Editora da Universidade Estadual de Campinas, 1989. cap. 1, p. 19-34. (Coleção linguagem-crítica).

KÖPKE, Barbara; SCHMID, Monica S. Language attrition: the next fase. In: SCHMID, Monica S. et al. First language attrition: interdisciplinary perpective on methodological issues. Amsterdam/Philadelphia: John Benjamins, 2004. 2004. p. 1-42.

LEONE, Fulvio. I pronomi personali di terza persona: l'evoluzione di un microssistema nell'italiano di fine millennio. Roma: Carocci, 2003. 
LORENZETTI, Luca. L'italiano contemporaneo. Roma: Carocci, 2002.

NEVES, Maria Helena de Moura. Gramática de usos do português. São Paulo: Ed. UNESP, 2000.

PERINI, Mário A. 2002. Modern Portuguese: a reference grammar. New Haven \& London: Yale University Press, 2002.

RASO, Tommaso. L'erosione linguistica dei madrelingua colti in contatto prolungato col portoghese brasiliano: un progetto in corso. In: XI CONGRESSO NACIONAL DA ABPI, IV ENCONTRO INTERNACIONAL DE ESTUDOS ITALIANOS E I JORNADA DE ITALIANÍSTICA DO MERCOSUL, 2005, Foz do Iguaçu. Atas... No prelo.

RASO, Tommaso. L'italiano parlato a San Paolo da madrelingua colti: primi sondaggi e ipotesi di lavoro. Revista de Italianística, São Paulo, n. 8, p. 9-49, 2003.

REVISTA DE ITALIANÍSTICA. São Paulo: Faculdade de Filosofia, Letras e Ciências Humanas da USP, n. 5, ano V. 1997. $291 \mathrm{p}$.

SCHMID, Monica S. et al. First language attrition: interdisciplinary perpective on methodological issues. Amsterdam/Philadelphia: John Benjamins, 2004.

SELIGER, Herbert W.; VAGO, Robert M. (Orgs.). First language attrition. Cambridge: Cambridge University Press, 1991.

SILVA, Rosa Virgínia Mattos. Variação, mudança e norma: movimentos no interior do português brasileiro. In: BAGNO, Marcos. (Org.). Linguística da norma. São Paulo: Loyola, 2002.

UNIVERSIDADE FEDERAL DO RIO DE JANEIRO. Faculdade de Letras. Projeto norma linguística urbana cul$t a-R J$ : banco de dados. Disponível em: <http://www.letras.ufrj.br/nurc-rj/>. Acesso em: 21 mar. 2007.

UNIVERSITÀ DI FIRENZE. Laboratorio di Linguistica del Dipartimento di Italianistica. Disponível em: $<$ http://lablita.dit.unifi.it/corpora/>.

VANELLI, Laura. "Punti di crisi” nell'italiano contemporaneo. In: CARDINALE, Ugo (Org.). Insegnare l'italiano nella scuola del 2000. Padova: Unipress, 1999. p. 99-121. 